\title{
Repercussões contemporâneas da Teoria Crítica: o debate entre Nancy Fraser e Axel Honneth sobre redistribuição e reconhecimento
}

Ana Crhistina Vanali ${ }^{1}$

Resumo: O debate entre Nancy Fraser e Axel Honneth sobre redistribuição e reconhecimento abarca uma multiplicidade de questões. Tomando como fio condutor a pergunta acerca da possibilidade de compreender o conjunto de injustiças existentes a partir do conceito de reconhecimento ou da necessidade de recorrer ao par conceitual redistribuição e reconhecimento, este artigo tem como objetivo entender a discordâncias das teorias sociais de Honneth e de Fraser. A partir de uma reconstrução das críticas dirigidas pelos autores ao dualismo social de Jürgen Habermas, bem como das diferentes teorias sociais que desenvolvem com o intuito de resolvê-las, procuraremos também mostrar que as saídas encontradas por eles a essas dificuldades estão no centro do debate sobre redistribuição e reconhecimento e que Fraser, ao desenvolver um dualismo social perspectivo, adota uma posição intermediária àquelas sustentadas por Honneth e Habermas.

Palavras-Chave: redistribuição, reconhecimento, teoria social, Nancy

Fraser, Axel Honneth

\footnotetext{
${ }^{1}$ Possui graduação em Ciências Sociais pela Universidade Federal do Paraná (1995) e mestrado em Antropologia Social pela Universidade Federal do Paraná (2002). Tem experiência na área de Antropologia, com ênfase em Etnologia Indígena do Paraná e História do Paraná. Atualmente é doutoranda em Sociologia na UFPR (linha de pesquisa: Sociedade e Estado). Membro do grupo de pesquisa NEP (Núcleo de Estudos Paranaenses-CAPES) e do grupo Pensamento social, intelectuais e circulação de ideias.
} 


\section{Introdução}

O debate sobre redistribuição e reconhecimento mobilizou e continua a mobilizar diversos autores, porém é o livro "Redistribuição ou Reconhecimento? Uma controvérsia político-filosófica", composto por textos de Nancy Fraser e Axel Honneth, que aparece como principal referência para aqueles que procuram marcar sua posição a respeito do que seria necessário atualmente para a realização da justiça: redistribuição, reconhecimento, ou ambos? O estabelecimento do debate sobre justiça nesses termos se deve, contudo, à publicação, do artigo de Nancy Fraser, "Da redistribuição ao reconhecimento? Dilemas da justiça na era pós-socialista"2. Nesse artigo, Fraser diagnostica uma crescente polarização entre aqueles que veem na redistribuição de recursos e riquezas a solução para o conjunto de injustiças hoje existentes $^{3}$ e aqueles que veem exclusivamente na obtenção do reconhecimento social essa mesma solução ${ }^{4}$. Essa polarização, por sua vez, estaria se encaminhando na direção da substituição de

\footnotetext{
${ }^{2} \mathrm{O}$ artigo de Fraser pode ser visto como o ponto inicial do debate sobre redistribuição e reconhecimento. Isso, contudo, não significa que a questão não se colocasse antes. Pelo contrário, nesse artigo, Fraser diagnostica uma situação pré-existente. A disputa entre representantes de ambos os lados já se fazia presente, mesmo que não tivesse sido tematizada nos termos propostos por Fraser (Fraser, 2001).

${ }^{3}$ Dentre aqueles que teriam tentado conceitualizar as formas socioeconômicas de injustiça, Fraser cita Karl Marx, John Rawls, Amartya Sen e Ronald Dworkin (Fraser, 2001, p.249).

${ }^{4}$ Dentre aqueles que teriam dado uma posição de centralidade ao reconhecimento, Fraser cita Charles Taylor, Axel Honneth, Patricia Williams e Iris Marion Young (Fraser, 2001, p.250-1).
} 
reivindicações e preocupações relativas à redistribuição econômica por aquelas pautadas pelo reconhecimento das diferenças. Segundo Fraser, o fim do "socialismo real", com a queda do muro de Berlim, seguida pelo fim da URSS, em conjunto com o acelerado processo de globalização, teriam levado à politização das diferenças étnicas e culturais e à despolitização da economia, cada vez menos contestada pelos movimentos sociais (Fraser, 1997, p.1-3). A busca pela igualdade social, que teria pautado as lutas políticas por mais de um século, estaria, assim, sendo substituída pela luta pelo reconhecimento das diferenças, central para os chamados "novos" movimentos sociais. No cenário político contemporâneo, afirma Fraser, o reconhecimento cultural desloca a redistribuição material como medida para sanar as injustiças e a luta por reconhecimento se torna a forma paradigmática de conflito, fazendo com que a dominação cultural suplante a exploração como injustiça fundamental (Fraser, 2001, p.245).

De acordo com esse diagnóstico, retomado posteriormente por Fraser no artigo com o qual abre a controvérsia com Axel Honneth, estaríamos diante de um mundo marcado pela dissociação, tanto na esfera política quanto na acadêmica, entre duas visões distintas acerca do que seria necessário para a realização da justiça. Enquanto alguns veriam na economia a causa última de todas as injustiças e defenderiam a redistribuição como a única forma de saná-las, outros teriam procurado entender o conjunto das injustiças existentes como consequências de padrões hierárquicos de valoração cultural, cuja 
alteração exigiria que todos fossem igualmente reconhecidos, mesmo em suas diferenças. Em ambos os casos, no entanto, o resultado é semelhante. A realização da justiça requereria apenas uma coisa: ou só redistribuição, ou só reconhecimento, não sendo necessário, nem mesmo possível, combinar as duas coisas. A existência de duas concepções de justiça mobilizadas pelos movimentos sociais em suas reivindicações não teria, então, caminhado na direção da integração de ambas, mas na do estabelecimento de uma acirrada disputa entre os defensores de cada uma delas.

O surgimento do debate sobre redistribuição e reconhecimento tem como pano de fundo o diagnóstico de Fraser de um cenário de polarização política e intelectual marcado por um quase abandono de reivindicações por redistribuição igualitária e por um aumento significativo de mobilizações sociais em torno de questões culturais ligadas ao reconhecimento e à diferença ${ }^{5}$. É a esse cenário que Fraser procura se contrapor, ao afirmar que a antítese presente em proponentes de ambos os lados é falsa e ao defender que a realização da justiça requer hoje tanto redistribuição material quanto reconhecimento cultural. Como, segundo ela, não seria possível remeter o conjunto das injustiças sociais existentes a uma única origem, uma vez que as sociedades contemporâneas estariam perpassadas por pelo menos dois

\footnotetext{
${ }^{5}$ Jürgen Habermas (Habermas, 2012) apresenta diagnóstico semelhante ao elaborado por Fraser, apontando também para uma mudança no interior do cenário político contemporâneo, cuja atenção teria se voltado para questões relacionadas à identidade e à diferença em detrimento de questões econômicas, antes predominantes.
} 
diferentes mecanismos sociais - os econômicos e os culturais -, que produziriam tipos distintos de injustiça, combater qualquer um deles isoladamente não seria suficiente. É, portanto, por possuírem origens sociais distintas, diz Fraser, que os dois diferentes tipos de injustiça existentes exigem de uma teoria social crítica que procure abarcá-los que ela seja dualista; da mesma forma, afirma ela, para que ambos sejam remediados, se fazem necessárias mudanças tanto na economia, através de medidas de redistribuição, quanto nos padrões culturais de valoração, por meio do reconhecimento ${ }^{6}$. Isso não significa, contudo, que as esferas da economia e da cultura se encontrem absolutamente diferenciadas. Pelo contrário, Fraser as vê como esferas de tal forma interligadas, que cada uma delas poderia, inclusive, levar ao estabelecimento de injustiças que estariam, em princípio, relacionadas à outra: a cultura poderia gerar, assim, injustiças relativas à redistribuição, e a economia, da mesma forma, injustiças relativas ao reconhecimento. No entanto, mesmo assumindo que mecanismos econômicos e culturais estão interligados e se reforçam mutuamente, Fraser acredita que não é possível compreender qualquer um deles como a causa última das injustiças sociais - a cultura não reflete, como superestrutura, a economia, nem esta pode ser entendida como um simples reflexo daquela -, motivo pelo qual ambos teriam de ser

\footnotetext{
${ }^{6}$ Fraser parece defender que o objetivo de sua teoria é integrar as diferentes demandas dos movimentos sociais. Contudo, sempre que ela procura justificar a validade das exigências de redistribuição e reconhecimento, ela se volta para sua teoria social dualista e não para o conjunto das demandas dos movimentos sociais (Fraser, 2001).
} 
entendidos em suas especificidades. Nesse sentido, embora afirme que os mecanismos que geram as disparidades sociais não podem ser claramente distinguidos no interior da sociedade, Fraser defende que cada um deles remonta a um tipo de injustiça que não pode ser reduzido ao outro. Embora não possam ser pensadas separadamente, cada uma dessas duas exigências de justiça - trazidas à tona por movimentos sociais - colocaria em xeque duas formas relativamente distintas de injustiça presentes nas sociedades capitalistas contemporâneas. Cada um dos polos da disputa apresentada estaria, dessa maneira, parcialmente correto, mas ambos teriam de ser devidamente integrados para possibilitarem uma visão mais ampla da sociedade. Não se poderia, por um lado, descartar as lutas por igualdade social, taxando-as de ultrapassadas e insensíveis à diferença, num mundo em que as desigualdades materiais são exacerbadas e, além disso, crescentes. Nem seria possível, por outro lado, descartar as lutas por reconhecimento como ideológicas, afinal existiriam também formas de subordinação social ligadas a padrões hierárquicos de valoração cultural que impediriam a realização da justiça, entendida por ela como paridade de participação. Nem só redistribuição, nem só reconhecimento. Segundo Fraser, precisamos de ambos, motivo pelo qual tais exigências devem ser integradas, e não colocadas como modos opostos de pensar ou reivindicar justiça hoje. Possibilitar essa integração é, assim, o que Fraser estabelece como seu objetivo. 
De acordo com Fraser tanto uma visão economicista, que reduza as injustiças existentes àquelas referentes à redistribuição, quanto uma culturalista, que as reduza àquelas referentes ao reconhecimento, manifestariam compreensões simplistas e incompletas das práticas sociais. Fraser rejeita qualquer teoria que procure identificar uma única causa para todas as injustiças sociais e se contrapõe, nesse sentido, à proposta de Axel Honneth, cuja teoria busca compreender todas as formas de injustiça por meio da chave conceitual do reconhecimento. Partindo de uma reatualização dos escritos hegelianos do período de Jena e da utilização da psicologia social de George Mead, Honneth elabora uma teoria que vê, na luta por reconhecimento, o motor dos conflitos sociais. Interpretado por Fraser como uma tentativa de reduzir as injustiças de caráter econômico à esfera cultural, o modelo teórico proposto por Honneth é acusado por ela de constituir um monismo teórico cultural reducionista, que, tomando a desigualdade econômica como o resultado de uma forma de falta de reconhecimento, não teria conseguido dar conta do conjunto de injustiças existentes, ou mesmo das diferentes rei- vindicações feitas pelos movimentos sociais que, segundo ela, não têm somente o reconhecimento recíproco como objetivo (Fraser, 2001, p.10-11). A leitura de Fraser da teoria de Honneth do reconhecimento a vê, assim, como uma das principais representantes das teorias culturalistas que identificaria na cultura a origem de todas as injustiças sociais. Nesse sentido, Fraser toma a teoria de Honneth como a expressão do 
deslocamento da redistribuição para o reconhecimento ou, como é também colocado por ela, do deslocamento da centralidade antes atribuída ao paradigma distributivo de justiça para a de um paradigma em cujo centro estariam questões relativas à identidade e à diferença.

Para Fraser, Honneth ao procurar compreender todas as formas de injustiça a partir do conceito de reconhecimento teria deixado de lado aquelas injustiças ligadas à economia e às reivindicações por redistribuição material que fazem parte da sociedade contemporânea e não podem ser ignoradas por aqueles que pretendem desenvolver uma teoria social crítica. Contudo, Honneth procura mostrar que as críticas de Fraser resultam de uma compreensão inadequada de sua teoria, uma vez que não atentam para o real significado atribuído por ele ao termo reconhecimento. Em uma primeira resposta a Fraser, Honneth afirma que a acusação da autora de que sua teoria seria culturalista e não daria conta de pensar as injustiças econômicas ou mesmo as lutas por redistribuição material se ancora em uma interpretação restrita do papel desempenhado por esse conceito no interior de seu modelo teórico. Reconhecimento, para ele, não é o mesmo que reconhecimento cultural. $\mathrm{O}$ conceito de Honneth de reconhecimento não remete diretamente à cultura, mas às expectativas morais de comportamento sustentadas pelos sujeitos frente a seus parceiros de interação. Segundo Honneth, na modernidade, os sujeitos formam, por meio de processos de interação social, expectativas morais de comportamento em três diferentes esferas de reconhecimento - a do amor, a do respeito e a da estima - que, 
quando rompidas, podem gerar um sentimento de desrespeito e injustiça. Quando compartilhado por vários atores, esse sentimento pode, por sua vez, desencadear um conflito social, entendido por ele como uma luta por reconhecimento. Assim, Honneth reconstrói os conflitos sociais como lutas morais por reconhecimento, porque é a experiência de injustiça e de desrespeito - atrelada as expectativas de reconhecimento - que os desencadeia.

Para Honneth, mesmo os conflitos por redistribuição só ocorrem quando a modificação da situação econômica ou a desigualdade material por eles problematizada é experienciada como injusta, razão pela qual ele afirma que lutas por redistribuição material são também lutas por reconhecimento. Honneth reconstrói os conflitos sociais como lutas por reconhecimento não em razão de questões teórico sociais, tal como Fraser, mas porque eles são desencadeados pelo sentimento de desrespeito que se segue da violação de expectativas bem fundadas de reconhecimento social. Nesse sentido, tanto as lutas por redistribuição material quanto aquelas por reconhecimento cultural seriam abarcadas por sua teoria do reconhecimento, na medida em que o sentimento de injustiça que as desencadeia também decorre de violações de expectativas de reconhecimento (Honneth, 2004, p.352).

Ao reconstruir os conflitos sociais como lutas por reconhecimento, Honneth não estaria excluindo ou negando a importância das reivindicações por redistribuição, mas reconstruindo-as de uma perspectiva normativa. A luta por reconhecimento não possui, 
consequentemente, um caráter meramente cultural ou identitário, mas um caráter moral que constitui, para ele, a gramática dos conflitos sociais. Deslocando a problemática da teoria social que fornece, para Fraser, a base para a reconstrução dualista que faz dos movimentos sociais, Honneth procura reconstruir e justificar moralmente esses conflitos, remetendo-os às experiências de desrespeito dos sujeitos, isto é, voltando- se para a motivação dos conflitos e não às origens sociais das injustiças que estão combatendo. A teoria de Honneth escapa das críticas dirigidas a ela por Fraser ao retomar o conceito de reconhecimento a partir do sentimento de desrespeito que mobiliza tanto as lutas por redistribuição quanto as por reconhecimento cultural. Partindo de uma teoria da intersubjetividade, Honneth nega que os conflitos políticos sejam simplesmente manifestações dos interesses de um conjunto de indivíduos; para ele, suas bases motivacionais devem ser reconstruídas a partir das expectativas morais atreladas à interação social e ao reconhecimento recíproco, e não a partir de um cálculo racional estrategicamente orientado (Honneth, 2003, cap.7). Por não conseguir estabelecer um vínculo estrutural entre a imanência e a transcendência e, além disso, por não tratar mais pormenorizadamente da motivação dos movimentos sociais, para Honneth, a teoria de Fraser não seria realmente crítica (Honneth, 2003c, p.274-285).

Em Luta por Reconhecimento, Honneth antecipa uma possível objeção a seu projeto, que apontasse para o fato de que nem todos os conflitos sociais são gerados por motivações de caráter moral, na 
medida em que conflitos pela concorrência de bens escassos seguem a lógica de um conflito movido por interesse.Com o intuito de indicar que mesmo esses conflitos podem ser pensados na chave conceitual do reconhecimento, uma vez que:

"o que é considerado um estado insuportável de subsistência econômica se mede sempre pelas expectativas morais que os atingidos expõem consensualmente à organização da coletividade. Por isso, o protesto e a resistência prática só ocorrem em geral quando uma modificação da situação econômica é vivenciada como uma lesão normativa desse consenso tacitamente efetivo". (Honneth, 2003, p.160-165).

A motivação e a justificação daquilo que os atores sociais reivindicam estão ligadas às maneiras por meio das quais determinadas situações sociais impedem a autorrealização pessoal Ao tratar do debate sobre redistribuição e reconhecimento em um nível distinto e mais abstrato do que aquele colocado inicialmente por Fraser, Honneth diz:

"por mais fundamentais que as questões de teoria social sejam, [...] elas desempenham apenas um papel subordinado no debate entre Fraser e eu. No primeiro plano, está a questão geral de quais ferramentas categoriais são mais promissoras para renovar a intenção da teoria crítica de, ao mesmo tempo, articular apropriadamente e justificar moralmente as reivindicações normativas dos movimentos sociais" (Honneth, 2003, p.135) 
É, assim, recorrendo ao monismo moral-motivacional presente nas experiências de injustiça, que decorreriam do rompimento de relações de reconhecimento, e não a questões acerca da origem social das injustiças, que Honneth procura rebater as críticas de Fraser. Tal saída não é, contudo, aceita pela autora como uma resposta adequada às questões por ela colocadas. Mesmo assumindo que haja discordâncias significativas no que se refere às bases normativas de suas teorias e às diferentes reconstruções que fazem da normatividade dos conflitos sociais e de suas motivações, Fraser defende que a disputa entre o monismo de Honneth e seu dualismo perspectivo não se situa nesses níveis, onde ambos desenvolvem, a partir de Jürgen Habermas, um paradigma crítico monista e reconstroem os conflitos sociais de um ponto de vista normativo. Assim, embora aceite que as questões levantadas por Honneth coloquem novos e importantes pontos na pauta do debate entre eles, Fraser insiste que a disputa entre o dualismo perspectivo desenvolvido por ela e o monismo proposto por ele diz respeito às diferentes teorias sociais presentes em seus modelos teóricos. E isso não apenas porque o dualismo defendido por ela tem como base sua teoria social, mas também porque, para ela, o diagnóstico das injustiças sociais não pode partir do sentimento subjetivo de desrespeito, mas apenas de uma teoria social democraticamente informada, que esteja apta a identificar os diferentes mecanismos sociais que originam as relações de dominação (Fraser, 2003, p. 201-211). Assim, se Honneth procura mostrar que o dualismo 
de Fraser poderia ser abarcado pelo monismo proposto por ele, na medida em que tanto os movimentos sociais por redistribuição quanto os por reconhecimento se originam do sentimento de desrespeito e poderiam ser, portanto, reconstruídos como lutas por reconhecimento, Fraser se contrapõe à sua proposta. Para ela, a estratégia adotada por Honneth não responde às questões por ela levantadas e pode, além disso, levar ao estabelecimento de algumas dificuldades, uma vez que toma o sentimento de desrespeito como o indicador da presença de patologias, sem, contudo, apontar para suas causas sociais, que precisariam ser devidamente identificadas para que ele pudesse elaborar uma teoria do poder apta a diagnosticar as relações de dominação presentes nas sociedades capitalistas contemporâneas. De acordo com Fraser, identificar a base motivacional dos conflitos sociais, como propõe Honneth, não é suficiente. O importante, no que diz respeito ao diagnóstico de patologias sociais, é identificar, a partir de uma teoria social, os mecanismos que as geram. Afinal, mesmo que Honneth tenha razão e as lutas por redistribuição sejam motivadas pelo sentimento de desrespeito, disso não decorreria que as desigualdades materiais questionadas possam ser entendidas como consequências de uma aplicação determinada de normas sociais ou resultem de relações assimétricas de reconhecimento. Recusando, assim, uma primeira estratégia utilizada por Honneth em sua resposta, Fraser afirma que a identificação das injustiças existentes não pode partir de experiências subjetivas de desrespeito, inacessíveis ao teórico, mas somente da 
identificação dos mecanismos sociais que geram impedimentos à participação paritária de todos na interação social.

Ao defender a importância de um diagnóstico de patologias sociais apto a apontar para os bloqueios sociais à emancipação, Fraser recoloca, então, o debate entre eles no nível da teoria social. E, de acordo com a autora, é particularmente no tocante a essa questão, relativa às relações de poder presentes na sociedade contemporânea, que a teoria do reconhecimento proposta por Honneth não empregaria ferramentas conceituais adequadas. $\mathrm{E}$ isso ocorre não porque ele se esquive por completo de questões relativas à teoria social, mas porque parte de uma compreensão monista e não dualista das sociedades capitalistas contemporâneas. Mesmo que o foco de Honneth, em sua primeira resposta a Fraser, não esteja em suas discordâncias a respeito do funcionamento da sociedade ou na identificação dos mecanismos sociais que levam ao estabelecimento das injustiças, sua teoria do reconhecimento pressupõe uma teoria social. Teoria na qual a interação social desempenha um papel central, mesmo no que diz respeito à economia. Embora afirme que o funcionamento do mercado capitalista não pode ser inteiramente explicado a partir de valores culturais e, nesse sentido, não aceite o rótulo de culturalista dado por Fraser à sua teoria, Honneth defende que as formas sociais de interação possuem primazia sobre as formas sistêmicas de integração, isto é, que a cultura possui certa primazia frente a economia. Primazia que remete a um importante ponto de discordância entre ambos. Afinal, para Fraser o funcionamento 
da economia teria se diferenciado relativamente das formas de interação social e precisaria ser entendido em suas especificidades. Para ela, mesmo que a cultura e a economia, ou a interação social e a sistêmica, permaneçam interligadas, elas teriam se diferenciado no decorrer do processo de modernização social e não poderiam, por isso, ser explicadas uma a partir da outra. Nenhuma dessas duas esferas sociais possuiria primazia sobre a outra, e é exatamente por isso que Fraser defende a necessidade de que injustiças culturais e econômicas, bem como exigências de redistribuição e reconhecimento, sejam diferenciadas. Conclusão que não é compartilhada por Honneth, para quem também a economia e, portanto, as desigualdades materiais estão fundamentalmente atreladas a relações de reconhecimento, que perpassariam e guiariam o funcionamento de todas as esferas sociais. Honneth possui, nesse sentido, uma compreensão distinta da de Fraser sobre o papel exercido por normas e valores no interior da economia e no processo de desenvolvimento social. Como diz Honneth:

"Como a integração de todas as outras esferas, o desenvolvimento do mercado capitalista só pode ocorrer na forma de um processo de negociação simbolicamente mediado, que seja dirigido pela interpretação de princípios normativos subentendidos. [...] Na expansão contemporânea do capitalismo, nem mesmo processos econômicos são simplesmente não-normativamente mediados". 2003, p.288-289). 
Honneth parece afirmar que não é possível distinguir - tal como o faz Fraser - os mecanismos econômicos de normas e valores sociais, uma vez que mesmo o funcionamento do sistema capitalista dependeria das expectativas daqueles por ele afetados e seria dirigido "pela interpretação de princípios normativos subentendidos". Ao contrário de Fraser que, rearticulando o dualismo social de Habermas entre sistema e mundo da vida, defende a necessidade de diferenciar os mecanismos econômicos dos culturais, Honneth defende que mesmo os mecanismos responsáveis pelo funcionamento da economia dependem fundamentalmente da interação social e, portanto, de valores culturais. Contrapondo-se a Fraser, mas também a Habermas, Honneth afirma que mesmo os imperativos do capitalismo estão atrelados a expectativas normativas e a relações de reconhecimento. Motivo pelo qual, para ele, também as injustiças materiais podem ser compreendidas como injustiças ligadas a relações assimétricas de reconhecimento e não diretamente como consequências de mecanismos econômicos relativamente autônomos. As diferentes concepções que Fraser e Honneth possuem sobre o funcionamento das sociedades capitalistas contemporâneas e, principalmente, os diferentes estatutos que atribuem à economia desempenham, assim, uma posição de centralidade na controvérsia que se estabeleceu entre eles sobre redistribuição e reconhecimento. No centro do debate está uma questão problematizada por eles já no prefácio do livro, onde se perguntam: 
“... o capitalismo, tal como ele existe hoje, deve ser compreendido como um sistema social que diferencia uma ordem econômica, que não é diretamente regulada por padrões institucionalizados de valores culturais, de ordens que o são? Ou deve a ordem econômica capitalista ser entendida, ao contrário, como uma consequência de um modo de valoração cultural que está atrelada, desde o início, a formas assimétricas de reconhecimento? Em seu nível mais profundo, este livro tenta colocar essa questão teoricamente e desenvolver um quadro comum que consiga acessar nossas respostas divergentes. (Fraser; Honneth, 2003, p.5)

Se recolocamos, como Fraser, o foco do debate sobre redistribuição e reconhecimento no nível da teoria social, nos deparamos com as diferentes concepções sustentadas pelos autores sobre a ordem econômica e seu vínculo com as relações de reconhecimento existentes. $\mathrm{O}$ debate sobre redistribuição e reconhecimento nos remete, assim, a uma disputa entre as diferentes compreensões sustentadas pelos autores a respeito do modo de funcionamento do capitalismo contemporâneo e sua relação com a cultura, ou com normas e valores intersubjetivamente elaborados. Compreensões que, embora distintas, possuem uma origem comum. Afinal, tanto o monismo teórico de Honneth como o dualismo perspectivo de Fraser são desenvolvidos com o objetivo de dar conta das dificuldades que ambos identificam no modelo teórico de Habermas em Teoria da Ação Comunicativa. 
Honneth e Fraser em torno do dualismo social: retomando Habermas

Os trabalhos de Nancy Fraser e Axel Honneth são fortemente marcados pela obra de Jürgen Habermas, cuja influência é decisiva em boa parte das questões em disputa no debate entre eles sobre redistribuição e reconhecimento. A própria mudança de paradigma efetuada por Habermas no interior da teoria crítica é central para o desenvolvimento das bases normativas dos modelos críticos de Fraser e Honneth. A influência desse autor nos modelos teóricos de Fraser e Honneth se estende, contudo, para além disso. O trabalho de Habermas constitui também a principal referência desses autores no que diz respeito às teorias sociais que elaboram. Nesse caso, contudo, a retomada da teoria de Habermas parece adquirir um outro estatuto, uma vez que os deslocamentos efetuados por eles, relativos ao dualismo social habermasiano, parecem tomar forma de uma contraposição. A teoria social apresentada por Habermas está, assim, no horizonte de Fraser e Honneth, mas é em contraposição a ela que cada um deles vai desenvolver sua própria teoria, mesmo que retomem alguns de seus aspectos. Contraposição que é central ao debate sobre redistribuição e reconhecimento, cujo pano de fundo é uma disputa entre as diferentes saídas apresentadas por Fraser e Honneth às dificuldades que identificam na teoria social e no diagnóstico de patologias sociais defendido por Habermas em Teoria da Ação Comunicativa. Nessa obra, 
Habermas apresenta uma teoria da modernização social nos termos de um processo de racionalização da sociedade. Segundo Habermas, as formas de interação social presentes nas sociedades tradicionais, onde toda estrutura e organização estariam vinculadas a visões religiosas e metafísicas de mundo, passaram por um processo de racionalização por meio do qual diferentes formas de reprodução e integração social teriam se diferenciado. Assim, se a organização das sociedades tradicionais dependia diretamente da normatividade assegurada por visões de mundo compartilhadas e podia ser adequadamente explicada apenas a partir de sua ordem normativa, o mesmo não ocorreria em sociedades modernas, cuja organização sistêmica não mais refletiria a normatividade social, agora racionalizada. Nas sociedades modernas o sistema não apenas teria deixado de refletir o mundo da vida, como teria se tornado independente dele e não poderia mais ser explicado do ponto de vista da normatividade social. Sociedades modernas seriam, assim, dualistas. Motivo pelo qual, para Habermas, uma análise adequada dessas sociedades precisa levar em consideração tanto o ponto de vista do mundo da vida, quanto o do sistema (Habermas, 2012).

Habermas consolida uma distinção entre duas esferas sociais:

1. uma dessas esferas corresponderia ao mundo da vida, cuja reprodução ocorre por meio de ações comunicativas. 
2. outra corresponderia ao que ele chama de sistema, composto de dois subsistemas, cuja reprodução se dá por meio de ações instrumentais.

O dualismo habermasiano, que distingue o sistema do mundo da vida, refere- se, assim, à identificação, na sociedade, de duas esferas sociais responsáveis, respectivamente, pela reprodução material e simbólica da sociedade, que estão ligadas, por sua vez, às duas racionalidades reconstruídas por Habermas a partir de ações instrumentais e comunicativas. No que se refere à reprodução material, responsável pelo desenvolvimento do sistema (economia e burocracia), a coordenação dos diversos objetivos dos sujeitos seria estratégica e livre, portanto, de normas. A reprodução simbólica, responsável pelos desenvolvimentos da cultura, da sociedade e da formação da personalidade, por outro lado, teria como base uma forma comunicativa de coordenar objetivos que, normativamente mediada, estaria orientada para o entendimento. Essa distinção entre duas esferas sociais e duas formas de reprodução social, problematizada por diversos autores e atenuada posteriormente por Habermas, é também fortemente criticada por Honneth, que procura desenvolver uma teoria social crítica na qual normatividade e poder pudessem ser entendidos em suas inter-relações. Para ele, a distinção proposta por Habermas entre duas racionalidades, dá lugar a uma distinção entre duas esferas sociais. Com essa mudança, afirma Honneth, o desenvolvimento da sociedade, antes pensado a partir 
das lutas entre os diversos grupos sociais pela definição de normas e instituições, passa a ser conceitualizado nos termos de um processo de diferenciação social que dá lugar a um conflito entre a pressão para adaptação exercida pelas organizações racionais voltadas a fins, o sistema, e as esferas de ação organizadas comunicativamente, o mundo da vida, cujo papel, nesse desenvolvimento, seria o de resistir ou não a essa pressão, ou ainda, e nisso estaria seu caráter emancipatório, regular essas organizações. Em detrimento de uma primeira formulação de sua teoria, na qual as relações de dominação eram pensadas no interior das esferas comunicativas, que moldariam as próprias instituições, Habermas teria posteriormente excluído das interações sociais as relações de dominação, que passaram, a partir de então, a ser concebidas como colonizações do mundo da vida pelos sistemas econômico e burocrático. Com isso, afirma Honneth, o dualismo social desenvolvido por Habermas não mais daria conta de compreender aquilo que denomina de reprodução simbólica da sociedade, nem de explicar como se reproduziriam as esferas chamadas por ele de sistêmicas, onde os conflitos sociais também teriam um papel ativo e determinante. O desenvolvimento dado por Habermas a seu modelo teórico estabeleceria, de acordo com Honneth, duas ficções teóricas:

1. a de um sistema que teria se diferenciado do mundo da vida e se tornado um meio não-linguístico de coordenação de objetivos; 
2. a de um mundo da vida isento de quaisquer relações de poder e de dominação, onde o processo de reprodução simbólica da sociedade ocorreria por meio de relações de comunicação linguisticamente mediadas.

No interior da teoria habermasiana, seria formada a ilusão de que haveria duas esferas sociais, cada qual responsável por diferentes aspectos da reprodução social - o material e o simbólico -, que seriam independentes entre si. Para Honneth, contudo, o funcionamento da economia e da burocracia estatal não pode ser compreendido como a mera expressão de um processo autônomo, descolado da interação social. Segundo ele, as expectativas intersubjetivas de reconhecimento e os conflitos sociais por elas gerados desempenham um papel ativo mesmo naquelas instituições referentes à organização do trabalho e à distribuição do poder. Como afirma ele:

\footnotetext{
"processos de valorização aparentemente anônimos são impregnados de regras normativas" (2001, p.292).
}

Não se poderia, portanto, falar em um sistema econômico ou burocrático, tal como o faz Habermas. Contrapondo-se a Habermas, Honneth procura, então, mostrar que o desenvolvimento do sistema capitalista e do aparelho burocrático do Estado é mediado por normas sociais e depende dos conflitos que moldaram e ainda moldam as 
instituições e práticas sociais em geral. Além disso, Honneth busca indicar que a dominação e as relações de poder, compreendidas por Habermas como ampliações do sistema em direção ao mundo da vida, precisam ser pensadas em conjunto com a comunicação, que está sempre perpassada por assimetrias. Seria preciso atrelar o desenvolvimento social como um todo a normas, bem como pensar as relações de poder presentes nas comunicações e relações de reconhecimento, ou seja, pensar a relação dessas normas com as formas de poder e dominação. É, então, com o objetivo de resolver as dificuldades que identifica em Habermas, que Honneth desenvolve uma teoria do reconhecimento, na qual afirma que a comunicação e as lutas por reconhecimento têm um papel ativo em todos os processos de reprodução social. As dificuldades que encontra na teoria de Habermas fazem com que Honneth defenda um monismo social, pautado por relações de reconhecimento. A crítica de Honneth - segundo a qual não seria possível entender a sociedade a partir de uma teoria que não aborde adequadamente a relação entre desenvolvimento social e lutas por reconhecimento - não se dirige, contudo, apenas a Habermas, mas também a Nancy Fraser. Afinal, como Habermas, Fraser defende que a economia se tornou relativamente distinta da interação social e, portanto, do âmbito no qual as normas sociais são elaboradas, denominado por ela de cultura.

Diferentemente de Honneth, Fraser aceita de Habermas a distinção entre dois mecanismos sociais. Por maiores que sejam as 
inter-relações entre as normas sociais e a economia, para Fraser, não é possível entender o funcionamento do capitalismo atual apenas a partir de normas sociais. Mesmo aceitando a impossibilidade de se conceber a economia como uma esfera social autônoma e isenta de normatividade, Fraser afirma que seu funcionamento não pode ser adequadamente entendido sem que se leve em consideração mecanismos sistêmicos que priorizam o lucro. Motivo pelo qual ela defende que a economia dispõe de relativa autonomia frente às normas sociais. Como Habermas, Fraser assume a existência de um certo dualismo social. $\mathrm{O}$ recurso de Fraser a Habermas não implica, contudo, que ela aceite como um todo as distinções dualistas estabelecidas por ele. Pelo contrário, ela faz diversas críticas à teoria social dualista desenvolvida por ele, e, afirmando a possibilidade de que ela seja entendida de dois modos, a saber, como substantiva ou analítica, parte da segunda para a elaboração de sua própria teoria social. Com essa teoria, no entanto, Fraser, como Honneth, procura tratar das dificuldades que encontra no modelo de Habermas. O que faz, por meio de um deslocamento, e não de um abandono da distinção entre sistema e mundo da vida e de uma alteração significativa na maneira como Habermas concebe as relações de poder e o surgimento das patologias sociais. A retomada da teoria social proposta por Habermas, feita pela autora, não Lfeminista é uniforme. Em um primeiro momento, ela busca confrontar alguns aspectos problemáticos que identifica no modelo habermasiano, passando, a recuperar nele aquilo que poderia ser visto como frutífero a 
uma teoria social. Fraser dirige a Habermas críticas semelhantes àquelas desenvolvidas por Honneth e aponta para possíveis saídas que serão posteriormente elaboradas por ela. Diferentemente das de Honneth, contudo, as saídas apresentadas por Fraser não caminham na direção de uma dissolução da distinção entre as esferas sociais, mas na formulação de um dualismo social perspectivo. Fraser procura mostrar que, apesar dos potenciais críticos presentes em sua teoria, Habermas não teria conseguido dar conta daquele que deveria ser seu papel como teórico crítico, a saber, aclarar, os objetivos do movimento feminista. Tomando, então, o modelo de Habermas tal como ele aparece em Teoria da Ação Comunicativa, Fraser procura explicitar que o dualismo social ali proposto é contraproducente, uma vez que encobre e mesmo reforça algumas das injustiças de gênero presentes na sociedade contemporânea. Fraser aponta para diversas deficiências presentes no modelo habermasiano. Deficiências muito semelhantes àquelas destacadas por Honneth. No que se refere à primeira dessas deficiências, as críticas dirigidas por Fraser a Habermas põem em questão o estatuto que ele teria dado à distinção entre duas esferas sociais, seja do ponto de vista da reprodução material e simbólica da sociedade, seja do ponto de vista das duas formas de integração por meio das quais a sociedade se reproduziria como um todo. Em um primeiro momento, Fraser problematiza a distinção que Habermas estabelece entre duas formas de reprodução social: 
1. a material, atrelada ao que ele chama de trabalho social, 2. a simbólica, que engloba a produção cultural, a integração social e os processos de individualização e socialização.

No que diz respeito a isso, Fraser procura apontar para a dificuldade que tal distinção teria no que se refere à classificação de diversas atividades sociais, tais como a criação de filhos que, segundo ela, é entendida por Habermas apenas como parte da reprodução simbólica da sociedade. Contrapondo-se a uma distinção forte entre esses dois tipos de reprodução social, Fraser afirma que a criação dos filhos possui elementos indispensáveis tanto para a reprodução simbólica quanto para a reprodução material da sociedade que, como é indicado por ela, não teria como ocorrer não fosse pela sobrevivência das crianças garantida, dentre outras coisas, pela alimentação dada aos filhos. Ao contrário do que se poderia pensar, a criação dos filhos envolve os dois tipos de reprodução social e não pode ser reduzida a nenhum deles em particular. $\mathrm{O}$ dualismo presente nessa atividade não se restringe, entretanto, a ela. Mesmo as atividades relacionadas ao trabalho social, responsável pela produção de bens e alimentos em geral, não podem ser entendidas apenas como responsáveis pela reprodução material da sociedade. Segundo ela, a própria produção ocorre por meio de relações culturalmente elaboradas e simbolicamente mediadas, dentre as quais, por exemplo, a divisão entre trabalhos 
masculinos e femininos. O próprio funcionamento da economia estaria, dessa forma, vinculado a valores e normas sociais. Assim, também a esfera do trabalho social possuiria elementos responsáveis, de alguma maneira, pela reprodução simbólica da sociedade e não poderia ser vista como normativamente neutra. Fraser afirma que uma distinção estanque entre duas formas de reprodução social é inadequada para a conceitualização das diferentes atividades responsáveis pela reprodução social como um todo. Com isso em vista, Fraser conclui pela necessidade de que as duas formas de reprodução social identificadas por Habermas sejam entendidas como dois diferentes aspectos da sociedade, que se encontram interligados. Conclusão que, mesmo sem rejeitar explicitamente uma distinção entre duas formas de reprodução social, nega claramente que ela possa ser entendida como uma distinção estanque, que atribui a diferentes esferas sociais - que também não devem ser clara ou objetivamente diferenciadas - a responsabilidade por um tipo específico de reprodução social. Fraser atenua, assim, a distinção entre as duas formas de reprodução social que identifica no trabalho de Habermas. A crítica de Fraser ao dualismo habermasiano não para, no entanto, por aqui, mas se estende aos diferentes níveis em que ele pensa a distinção social entre sistema e mundo da vida.

Considerando, então, uma segunda distinção proposta por Habermas, agora referente às duas formas de integração, a sistêmica e a social, Fraser busca mostrar que também elas não podem ser completamente distinguidas, tal como o faria Habermas. Questionando, 
mais uma vez, a possibilidade de que o dualismo habermasiano possa ser interpretado como uma distinção estanque ou substantiva entre diferentes formas de ação, integração e reprodução social, Fraser indica, a partir de elementos empíricos, que nem no interior da economia nem na família a integração seria absolutamente sistêmica ou social. Tanto uma quanto a outra são, segundo ela, perpassadas por diferentes formas de integração. Posicionando-se, então, criticamente frente a Habermas e defendendo uma posição que poderíamos aproximar da de Honneth, Fraser afirma que não é possível distinguir claramente entre uma esfera social absolutamente livre de normas e uma outra na qual relações de poder e imperativos econômicos não desempenham, em princípio, qualquer papel. Com o objetivo de criticar, em diferentes níveis, a defesa de um dualismo substantivo que poderia ser encontrado em Habermas, Fraser afirma, então, que:

“... em poucos, se é que em algum, dos contextos de ação humana as ações são coordenadas de forma absolutamente não-consensual e absolutamente nãonormativa. Por mais moralmente dúbio que seja o consenso e por mais problemático que seja o conteúdo e o status das normas, virtualmente todo contexto de ação humana envolve alguma forma de ambos. No mercado capitalista, por exemplo, trocas estratégicas e maximizadoras de utilidade ocorrem frente um horizonte de significados e normas compartilhados intersubjetivamente; agentes normalmente subscrevem mesmo que apenas tacitamente a noções comumente aceitas de reciprocidade e a alguma concepção compartilhada 
sobre os significados sociais dos objetos, incluindo que tipos de coisas são consideradas trocáveis. [...] O sistema econômico capitalista tem uma dimensão moral-cultural. Da mesma forma, poucos, se é que algum, dos contextos de ação humana são completamente destituídos de cálculo estratégico. “ (1987b, p.118)

Recusando uma das possíveis interpretações de Habermas, a qual "seria muito extrema para que fosse útil à teoria social" (1987b, p.117), Fraser defende uma posição bastante semelhante à de Honneth. Como ele, ela parece recusar que a economia e a burocracia estatal sejam realmente autônomas e procura indicar que talvez não haja qualquer contexto de ação humana que esteja, por um lado, livre de normas e valores compartilhados e, por outro, isento de relações de poder; chegando a criticar, inclusive, o uso que Habermas faz desse termo ao restringi-lo à esfera burocrática da sociedade. Nesse sentido, Fraser tenta não somente mostrar a impossibilidade de se estabelecer uma distinção substantiva entre as esferas sociais, bem como a de distinguir tão claramente entre as formas de ação que, conforme dito acima, não são unidimensionais. Impossibilidade e recusa que, no entanto, não a levam a questionar a própria divisão da sociedade entre sistema e mundo da vida, mesmo que o que ela virá a entender por sistema não possua a mesma força atribuída por Habermas a esse termo. Além disso, como Honneth, ela afirma que enxergar na sociedade apenas a tendência de ampliação do sistema para além de seus limites desejáveis é insuficiente, assim como o é a compreensão proposta por 
Habermas acerca das patologias sociais, cujas causas estariam, segundo ele, na colonização do mundo da vida pelo sistema. Ao questionar a separação colocada pelo texto de Habermas e mostrar que o funcionamento da economia depende de normas, Fraser afirma que é preciso perceber também como o próprio sistema está sendo influenciado a todo tempo pelo mundo da vida e incorpora, muitas vezes, valores ou significados sociais, instrumentalizando-os.

Apesar das semelhanças que possui com o modelo de Honneth, a teoria social desenvolvida por Fraser não abandona por completo o dualismo proposto por Habermas, mas relativiza suas fronteiras e examina suas interrelações. Tal abordagem, para ela, permite uma compreensão mais adequada da sociedade em seus diferentes aspectos, sem abrir mão de sua complexidade, ao mesmo tempo em que possibilitaria uma melhor conceitualização dos diversos mecanismos que dão origem às injustiças. Esses mecanismos devem ser também pensados no interior da interação social, que pode estar na origem de normas assimétricas. Tal como Honneth, Fraser procura, então, apontar para a necessidade de pensar as relações de poder também a partir das interações sociais, isto é, das relações comunicativas, sem o que, como afirma, teríamos uma concepção por demais simplificada e mesmo limitada das patologias sociais. Como diz Fraser, 
“... a abordagem de Habermas não consegue teorizar o caráter patriarcal, mediado por normas do sistema administrativo e econômico-oficial do capitalismo tardio. Da mesma forma, ele não consegue teorizar o caráter sistêmico, mediado pelo dinheiro e pelo poder, da dominação masculina na esfera doméstica do mundo da vida do capitalismo tardio. Consequentemente, sua tese da colonização não consegue compreender que os canais de influência entre instituições do sistema e do mundo da vida são multidirecionais" (1987b, p.137).

Tendo, em um primeiro momento, apontado para como o capitalismo não é absolutamente autônomo, mas depende de uma certa moralidade, o que implica uma primeira forma de regulação do sistema por normas comunicativas, Fraser defende, num segundo momento, que existiriam também outras normas - assimétricas - que, elaboradas intersubjetivamente, estruturam de alguma maneira o próprio funcionamento do sistema e constituem, por si só, patologias sociais. Esse é o caso da subordinação feminina, que teria parte de suas origens nas interações sociais que fazem parte do mundo da vida, e não pode ser entendida como um mero resultado da sua colonização sistêmica. Haveria, assim, patologias sociais cuja causa não estaria na ampliação do sistema, mas no "interior" do próprio mundo da vida. Patologias pensadas por ela a partir da distinção entre normas estabelecidas em contextos de interação normativamente assegurados, em contraposição às normas estabelecidas em contextos de interação comunicativos. Normas e valores poderiam ser, assim, o resultado de comunicações 
distorcidas, mas cujas distorções não teriam se originado do sistema, via monetarização ou burocratização, mas dos próprios contextos de interação que fazem parte do mundo da vida. É, então, na distinção entre esses dois diferentes tipos de normas sociais, encontrada por ela no próprio Habermas (Fraser, 1987a, p.142-143), que se localiza a origem do dualismo entre redistribuição e reconhecimento que Fraser apresenta. Assim, se Fraser parece direcionar críticas muito semelhantes às de Honneth a Habermas e aponta para praticamente os mesmos problemas no dualismo entre sistema e mundo da vida, é possível ver a origem das diferenças entre suas posições. Isso porque, enquanto Honneth procura mostrar que relações de poder fazem parte do "social" e que esse mesmo "social" é aquilo que estrutura o sistema, concluindo, em razão disso, pela necessidade de dissolver quaisquer dualismos e de pensar as relações de poder e a comunicação conjuntamente, Fraser, por sua vez, aceita que essas inter-relações existam, mas admite uma diferenciação, ainda que relativa, entre as esferas do sistema e do mundo da vida. Ao contrário de Honneth, portanto, Fraser assume uma certa diferenciação da economia que produziria, ela também, injustiças sociais. Contrapondo-se simultaneamente a Honneth e a Habermas, Fraser parece defender, com seu dualismo, uma posição intermediária à deles. Para ela, dissolver como um todo as distinções entre as esferas sociais e defender que a economia não tenha se diferenciado e não possua mecanismos relativamente autônomos não constitui um diagnóstico adequado da sociedade. Fraser retoma o dualismo de 
Habermas, mas, ao fazê-lo, torna as fronteiras entre a economia e a cultura fluídas, fazendo com que a distinção entre essas esferas sociais seja relativa e não substantiva.

Para ela, dissolver como um todo as distinções entre as esferas sociais e defender que a economia não tenha se diferenciado e não possua mecanismos relativamente autônomos não constitui um diagnóstico adequado da sociedade. Esta só poderia ser abarcada por meio de um dualismo social que, apto a perceber as particularidades das esferas sociais, conseguisse também pensar suas inter-relações e, mais do que isso, fazer sua crítica. Dualismo que, pensado a partir de Habermas, não se confunde com aquele proposto por ele. Afinal, o dualismo de Fraser aponta também para dois mecanismos geradores de injustiça na sociedade, que Habermas reduz a apenas um. Ao contrário dele, portanto, Fraser defende que seria preciso distinguir os mecanismos de interação social produtores de injustiça dos mecanismos sistêmicos produtores de injustiça e, por fim, a própria interação comunicativa, que estaria na base normativa de seu modelo teórico. $\mathrm{O}$ diagnóstico de época desenvolvido por Fraser faz, então, ao contrário de Habermas, uma distinção entre dois tipos de injustiça:

1. aquelas relacionadas à distribuição de bens materiais, ancoradas primordialmente na economia política e, portanto, em formas sistêmicas de integração; 
2. e as relacionadas ao reconhecimento, dependentes de padrões de valoração cultural e, consequentemente, de formas sociais de integração presentes na base do mundo da vida.

Esses dois mecanismos estariam, entretanto, interligados e não poderiam ser concebidos independentemente do outro, motivo pelo qual Fraser afirma que as injustiças relativas à redistribuição e ao reconhecimento não remontam exatamente à economia e à cultura. Fraser abandona, assim, a compreensão unilateral que Habermas sobre as patologias sociais. Desse modo, se Fraser retoma o dualismo habermasiano, ela o faz deslocando-o. Trata-se, para ela, de pensar as duas esferas sociais, a econômica e a cultural, que gerariam, por meio de dois mecanismos inter-relacionados, formas relativamente distintas de subordinação. Para Fraser, seria preciso não somente atenuar o dualismo proposto por Habermas, como também acrescentar à sua teoria uma noção expandida de patologias sociais, sem a qual não seria possível entender adequadamente uma parte das injustiças presentes hoje na sociedade, nas quais o que está em causa não é nem o sistema, nem sua intervenção no mundo da vida, mas os próprios significados e valores que, apesar de terem sido construídos socialmente, não são legítimos. Seria preciso atentar para as relações de dominação presentes na própria reprodução simbólica da sociedade, bem como questionar os mecanismos econômicos que geram impedimentos à participação 
paritária de todos na sociedade. A concepção habermasiana sobre a origem das patologias sociais seria, assim, unilateral. Preso ainda a uma chave "instrumentalista" ou economicista, ele não teria dado conta de parte das injustiças existentes, as quais já teriam sido, inclusive, questionadas pelos movimentos feministas ou anti-racistas que estão, em certa medida, lutando pela alteração de padrões sociais hierárquicos presentes na sociedade, isto é, pela alteração de conteúdos do mundo da vida, socialmente construídos. Contrapondo-se a Habermas, Fraser procura "desneutralizar" a economia, afirmando que ela está em disputa, e, além disso, examinar as relações de dominação presentes no interior da própria interação social. Esse objetivo é também o de Honneth, que, no entanto, acaba direcionando seus esforços para a elaboração de uma teoria na qual a comunicação dirige $o$ funcionamento de todas as esferas sociais, inclusive o da economia. $\mathrm{O}$ que o teria impedido de conceitualizar as injustiças de caráter econômico e de entender suas particularidades. Ao desenvolverem seus modelos críticos, Fraser e Honneth procuram, então, cada qual a seu modo, desenvolver teorias sociais que consigam dar conta daquilo que, para eles, a de Habermas não daria, isto é, da influência de normas no interior da economia e das assimetrias e relações de poder reproduzidas por meio da interação social. As saídas que apresentam são, contudo, distintas. E, é precisamente no que diz respeito a elas que se situa um dos principais pontos em disputa entre eles no interior do debate sobre redistribuição e reconhecimento. 


\section{Conclusão}

Ao criticar o dualismo social proposto por Habermas e afirmar que as lutas por reconhecimento seriam responsáveis pelo desenvolvimento da sociedade como um todo, Honneth propõe uma teoria social específica que, diferentemente daquela elaborada por Fraser, não é dualista. Embora assuma, em determinados momentos, que a economia e a burocracia estatal funcionem de modo relativamente inquestionado, Honneth sustenta que ambas dependem de que as normas sociais nas quais se baseiam sejam imbuídas de legitimidade pelos concernidos. Além disso, em diversos momentos, Honneth defende uma versão ainda mais forte de seu monismo social, segundo a qual o capitalismo não apenas dependeria do consentimento tácito dos concernidos, mas seria também regido por diferentes princípios de reconhecimento. Nessa versão, que consiste no principal alvo das críticas de Fraser, Honneth defende que, atualmente, a divisão do trabalho e o funcionamento da economia teriam deixado de ser diretamente regulados pelo princípio da honra e teriam passado a ser regulados pelo princípio meritocrático da "produção individual", ou pelo princípio democrático do "respeito igual". Como afirma ele:

“... com o estabelecimento gradual de um novo modelo de valor assegurado pela burguesia economicamente ascendente frente à nobreza, o 
princípio da honra baseado no estamento perdeu, inversamente, sua validade, de forma que a posição social do indivíduo se tornou agora normativamente independente de origem e posses. A estima que o indivíduo passou a merecer legitimamente não é mais decidida com base em seu pertencimento a um estamento com códigos de honra correspondentes, mas, pelo contrário, com base nas produções individuais no interior da estrutura da divisão de trabalho industrialmente organizada. [...] Uma parte da honra atribuída hierarquicamente foi, de certa forma, democratizada designando a todos os membros da sociedade igual respeito por sua dignidade e autonomia como pessoas de direito, enquanto outra parte foi, de certa forma, 'meritocratizada': cada um deveria desfrutar de estima social conforme sua produção enquanto um “cidadão trabalhador". ( 2001, p.165-166)

Com a revolução burguesa, a distribuição material, antes realizada e legitimada por meio de títulos de nobreza ou códigos de honra, teria passado a depender da aplicação de dois princípios normativos, ligados a duas diferentes esferas de reconhecimento, a da estima e a do respeito. Para Honneth, portanto, o surgimento do capitalismo corresponderia a uma alteração nos princípios normativos que justificam a distribuição de renda e a divisão social do trabalho, e não, tal como para Habermas, a autonomização ou diferenciação da economia frente à normatividade em geral. Os princípios normativos que regulam as relações de reconhecimento, das quais dependeria o desenvolvimento e as mudanças sociais em geral, possuem, assim, uma posição de centralidade na teoria social de Honneth. Para ele, não há 
mecanismos econômicos que funcionem quase que independentemente de relações comunicativas e que possam ser tomados como uma causa específica de injustiças sociais. As assimetrias relativas à divisão social do trabalho e à distribuição desigual de renda não se originariam diretamente de mecanismos do sistema econômico, mas de uma aplicação específica de diferentes princípios de reconhecimento que regulam o mercado. Nesse sentido, aqueles que visam a alterar a economia não devem lutar diretamente pela reestruturação de mecanismos sistêmicos, como defende Fraser, mas pela alteração dos princípios de reconhecimento que regem a economia. Lutas que poderiam mobilizar dois diferentes princípios de reconhecimento para justificarem suas demandas, o da igualdade de direitos ou o da estima social. Como afirma Honneth:

“... existem atualmente dois caminhos abertos para os sujeitos demandarem o reconhecimento da particularidade de sua situação de vida ou personalidade, para conseguirem lutar por uma maior quantidade de estima social e, consequentemente, mais recursos: Por um lado, até um determinado limiar, politicamente negociado, é possível mobilizar a aplicação de direitos sociais que garantam a todo membro da sociedade um mínimo de bens essenciais independentemente de sua produção; o caminho aberto com isso segue o princípio da igualdade de direitos na medida em que, por meio da mobilização argumentativa do princípio da igualdade, pode- se aduzir fundamentos normativos que façam com que um mínimo de bem estar econômico seja um imperativo do 
reconhecimento legal. Por outro lado, contudo, na realidade social cotidiana do capitalismo, existe também a possibilidade de apelar para as conquistas de alguém como algo 'diferente', uma vez que elas não recebem consideração suficiente ou estima social sob a estrutura hegemônica de valores prevalecente. Uma figura suficientemente diferenciada desse tipo de luta por reconhecimento só é possível, certamente, quando levamos em consideração o fato de que tanto a demarcação social de profissões quanto a forma da divisão social de trabalho é, como um todo, o resultado das valorações culturais das capacidades específicas para a produção. Hoje tem se tornado particularmente claro que a construção social dos campos de atividades profissionais é determinada e perpassada por preconceitos sobre o perfil e o limite das capacidades femininas. [...] Tudo isso mostra o quanto a legitimação da ordem de distribuição social deve a visões culturais sobre a contribuição de diferentes grupos ou estratos para a reprodução social. Não somente quais atividades podem ser valorizadas como 'trabalho' e, portanto, elegíveis à profissionalização, mas também quão alto deve ser o retorno social para cada atividade profissionalizada é determinado por um modelo de classificação e esquemas de valores que estão profundamente ancorados na cultura da sociedade capitalistaburguesa". (2003, p.181-182)

Dependendo da quantidade e do conjunto de bens sociais que a sociedade considera legítimo garantir a todos, independentemente da produção de cada um, teríamos uma economia mais ou menos liberal. Dependendo, por sua vez, das capacidades socialmente valoradas em uma sociedade, bem como do grau de estima de que disporiam os 
diferentes cargos e os grupos sociais que costumam preenchê-los, poderíamos analisar as bases salariais atribuídas às diferentes profissões. Dessa forma, para que as assimetrias de renda e de recursos fossem remediadas, seria preciso alterar, de dentro, as relações de reconhecimento que as regem e embasam normativamente e não, como afirma Fraser, regular ou alterar, de fora, os mecanismos sistêmicos da economia, através das medidas de redistribuição.

Para Honneth, então, a economia e seus mecanismos estão subordinados à interação social, motivo pelo qual eles não precisariam ser compreendidos em suas especificidades. Para Fraser, contudo, não é isso o que acontece. De acordo com ela, o funcionamento do sistema não depende diretamente de expectativas normativas, mas opera de maneira relativamente impessoal através de processos que priorizam a maximização do lucro. Nesse sentido, para Fraser, a tentativa de Honneth de entender a divisão social do trabalho e a diferença na distribuição de recursos por meio do conceito de reconhecimento fecha os olhos para a existência desses mecanismos e, por isso, não dá conta de analisar adequadamente a sociedade capitalista atual. Para Fraser, a resposta dada por Honneth às dificuldades que identifica no modelo teórico de Habermas não é plenamente satisfatória, mesmo que ele tenha apontado na direção correta. Recusando a possibilidade de que a sociedade possa ser compreendida de forma unilateral, Fraser defende, então, opondo-se a ele, a necessidade de pensar um dualismo social perspectivo. Como afirma ela, nesse sentido: 
“...o dualismo perspectivo assume que sociedades capitalistas diferenciam a ordem de um mercado sistemicamente integrado de ordens sociais reguladas por valores. Como resultado, tanto a integração sistêmica quanto a integração social são essenciais para essas sociedades. Ao contrário da abordagem de Honneth, portanto, a minha atenta para ambas dimensões e elucida suas interações mútuas." (2001, p.222)

Como mecanismos econômicos possuem certa autonomia frente a normas socialmente construídas, a complexidade e mesmo os diferentes aspectos das relações de dominação existentes exigiriam, para serem compreendidos, uma teoria social perspectivo-dualista, com a qual Fraser se afasta tanto de Honneth quanto de Habermas. Tendo em vista, a impossibilidade de estabelecer uma distinção rígida entre o sistema e o mundo da vida e repensando as diversas formas de interação entre ambos, bem como seu funcionamento, Fraser reformula, então, o dualismo habermasiano e desenvolve um dualismo perspectivo, com o qual procura apontar também para as diferentes origens das injustiças sociais. Nesse sentido, Fraser afirma que, nas sociedades modernas:

“... a estrutura de classes deixa de espelhar perfeitamente a ordem de status, mesmo que cada uma delas influencie a outra. Uma vez que o mercado não constitui o único e completamente difuso mecanismo de valoração, a posição no mercado não dita o status social. Padrões de valor cultural parcialmente resistentes ao mercado 
impedem que injustiças de distribuição se convertam inteiramente e sem exceções em injustiças de status. Má distribuição não necessariamente implica falta de reconhecimento, embora ela certamente contribua para a última. Similarmente, uma vez que nenhum princípio [...] constitui o único e completamente difuso princípio de redistribuição, o status não dita a posição de classe. Instituições econômicas relativamente autônomas impedem que injúrias de status se convertam inteiramente e sem exceções em injustiças de distribuição. A falta de reconhecimento não se converte diretamente em má distribuição, embora ela também certamente contribua para a última. Como resultado, não se pode entender essa sociedade atentando exclusivamente para uma única dimensão da vida social. Não se pode ler a dimensão econômica diretamente da subordinação cultural, nem a cultural diretamente da econômica. [...] Por fim, não se pode deduzir a má distribuição diretamente a falta de reconhecimento, nem a falta de reconhecimento a má distribuição.” (Fraser, 2001, p.53-54)

Defendendo uma posição intermediária entre aquelas presentes nos trabalhos de Honneth e Habermas, Fraser desenvolve uma teoria social que procura abarcar a complexidade dos aspectos sociais existentes. Teoria social que, como indicado acima, se encontra atrelada a um diagnóstico distinto daqueles apresentados por esses autores sobre as relações de dominação, uma vez que aponta para um dualismo também nas origens das injustiças sociais. Contrapondo-se, então, aos dois autores, Fraser adota uma posição intermediária que, mesmo sem negar o dualismo habermasiano entre sistema e mundo da vida, procura 
relativizar suas fronteiras e desenvolver uma teoria do poder que consiga atentar para as diferentes origens das patologias sociais, que Habermas e Honneth teriam compreendido de modo unilateral. Ao afirmar que as diferentes formas de injustiça existentes exigem de uma teoria que se pretenda crítica, hoje, que ela seja dualista, Fraser recusa tanto o monismo proposto por Honneth quanto o dualismo proposto por Habermas, bem como a compreensão unilateral que ambos possuem sobre o surgimento das patologias sociais. Distanciando-se de Habermas, ela examina os mecanismos patológicos presentes no próprio mundo da vida, assim como aqueles que têm como causa a economia, cujas fronteiras seriam, para ela, fluidas. Ao contrário de Honneth, por sua vez, ela mantém o conceito de sistema, na medida em que aceita, mesmo que parcialmente, a diferenciação e autonomização relativa da esfera econômica da sociedade, que estaria na origem de parte das injustiças sociais.

Assim, enquanto Honneth, partindo de determinadas críticas frente ao dualismo social presente em Teoria da Ação Comunicativa, desenvolve um monismo social centrado no conceito de reconhecimento, Fraser, partindo de críticas muito semelhantes, elabora um dualismo social perspectivo, com base no qual defende que as sociedades contemporâneas requerem tanto redistribuição quanto reconhecimento. A disputa entre o monismo do reconhecimento proposto por Honneth e o dualismo entre redistribuição e reconhecimento proposto por Fraser se estabelece, então, quando os 
autores procuram superar o dualismo social de Habermas e a compreensão que ele possui sobre a origem das patologias sociais em Teoria da Ação Comunicativa. A pergunta acerca da possibilidade de que o conjunto de injustiças existentes seja compreendido a partir do conceito de reconhecimento, ou acerca da necessidade de recorrer, para isso, ao par conceitual redistribuição e reconhecimento, nos remete a uma disputa entre Fraser e Honneth quanto aos diferentes caminhos adotados por eles na tentativa de superar os problemas que identificam no diagnóstico da sociedade proposto por Habermas. Em questão, no debate sobre redistribuição e reconhecimento, estão, assim, as diferentes teorias sociais elaboradas por Fraser e Honneth com o objetivo de superar as dificuldades que encontram em Habermas e de apresentar um modelo de teoria crítica que consiga diagnosticar os bloqueios e tendências à emancipação. Objetivo que nos remete à seguinte pergunta, que se encontra no centro do debate entre eles:

É mesmo possível, tal como defende Honneth, afirmar que os mecanismos econômicos dependem de um consenso normativo, isto é, é possível afirmar que o mercado capitalista e suas formas de distribuição de renda são possíveis apenas na medida em que se baseiam em relações de reconhecimento e dispõem de legitimidade da parte dos que são por ele afetados?

Tal posição teria como consequência a conclusão de que o conjunto de injustiças sociais existentes tem como causa relações assimétricas de reconhecimento e poderia ser adequadamente 
conceitualizado apenas a partir do conceito de reconhecimento. $\mathrm{Ou}$, ao contrário, é necessário estabelecer, como propõe Fraser, uma distinção entre duas esferas sociais que, mesmo interligadas, teriam se diferenciado e gerariam dois tipos de subordinação relativamente distintos? Isto é, se formas de integração econômicas podem ser ditas relativamente autônomas e levariam ao estabelecimento de injustiças que não poderiam ser adequadamente compreendidas como efeitos de hierarquias socioculturais. Caso no qual o dualismo de Fraser, que distingue as injustiças e as exigências relativas à redistribuição e ao reconhecimento, seria mais adequado do que o monismo de Honneth para diagnosticar as patologias sociais existentes. Afinal, nesse caso, seria preciso alterar tanto os padrões culturais de valoração, via reconhecimento, quanto reestruturar os mecanismos econômicos, via redistribuição, para que todos pudessem participar como pares da sociedade.

O debate entre Fraser e Honneth sobre redistribuição e reconhecimento põe em questão se é mesmo possível afirmar que o desenvolvimento da sociedade depende, como um todo, das relações de reconhecimento, ou se é preciso diferenciar, ainda que relativamente, a economia de outros âmbitos sociais regulados diretamente por normas. Independentemente da resposta que dão a essa questão, contudo, ambos os autores recusam que as injustiças possam ser adequadamente compreendidas a partir da tese da colonização do mundo da vida pelo sistema e apontam para a necessidade de que as relações de poder 
existentes sejam também pensadas a partir das interações sociais. Além disso, tanto Fraser quanto Honneth, cada um a seu modo, defendem que o sistema não é neutro e nem absolutamente autônomo, colocando-o novamente em disputa e recusando, com isso, elementos do modelo teórico de Habermas.

\section{Bibliografia}

AVRITZER, L. (2007). Do reconhecimento do self a uma política institucional de reconhecimento: uma abordagem polêmica entre Axel Honneth e Nancy Fraser. In: ANPOCS. GT: Teoria social, 31. Caxambu. 2007. Anais ANPOCS.

FRASER, N. (2001). "Da redistribuição ao reconhecimento? Dilemas da justiça da era pós-socialista". In: SOUZA, J. (Org.) Democracia hoje. Brasília: Editora Universidade de Brasília.

FRASER, N. ; HONNETH, A.(2003). Redistribution or recognition? A political-philosophical exchange. New York;London: Verso.

FRASER, N. (1987a). "A nova intransparência: a crise do Estado de Bem- Estar Social e o esgotamento das energias utópicas". Novos Estudos, São Paulo, CEBRAP, n.18, p.103-114.

FRASER, N. (1987b). "Que é crítico na teoria crítica? O argumento de Habermas e o gêneros". IN: BENHABIB, S. e CORNELL, D. Feminismo como crítica da modernidade. RJ: Rosa dos Tempos.

FRASER, N. (1997). Direito e democracia. Entre facticidade $e$ legitimidade. Rio de Janeiro: Tempo Brasileiro. 
HABERMAS. J.(2012). Teoria do agir comunicativo. 2 volumes. SP: Martins Fontes.

HONNETH, A. (2003). Luta por reconhecimento: a gramática moral dos conflitos sociais. São Paulo: Editora 34.

HONNETH, A. (2004). "Recognition and justice. Outline of a plural theory of justice". Acta Sociologica, London, v.47, n4, p.51-364.

HONNETH, A. (2008). "Trabalho e reconhecimento". Civitas, Porto Alegre, v. 8, n.1, p.46-67, jan./abr.

MATTOS, P. (2006). A sociologia política do reconhecimento. As contribuições de Charles Taylor, Axel Honneth e Nancy Fraser. São Paulo: Annablume.

MELO, R. (2013). A teoria crítica de Axel Honneth: reconhecimento, liberdade e justiça. SP: Editora Saraiva.

NEVES, P. (2005). "Luta anti-racista: entre reconhecimento e redistribuição". Revista Brasileira de Ciências Sociais, São Paulo, v. 20, n. 59, p.81-95.

PINTO, C. (2008). "Nota sobre a controvérsia Fraser-Honneth informada pelo cenário brasileiro". Lua Nova, São Paulo, CEDEC, n.74, p.35-58.

SILVA, F. (2007). "Nancy Fraser e Seyla Benhabib: uma disputa entre modelos críticos". In: NOBRE, M. Curso livre de teoria crítica. São Paulo: Papirus.

STRAUSS, A. (1956). The social psychology of Georg Mead. Chicago: Phoenix Books. 


\section{Internet}

Entrevista de Axel Honneth a Luiz Repa e Marcos Nobre. Folha de São Paulo, 11 de outubro de 2003. Acesso em 17 de janeiro de 2014.

Entrevista de Axel Honneth a Rúrion Melo e Marcos Nobre. Folha de São Paulo, 09 de setembro de 2009. Acesso em 17 de janeiro de 2014. 